\title{
Diet and partial digestion in sections of the alimentary tract of the sheep
}

\author{
By A. ROGERSON \\ East African Veterinary Research Organization, Muguga, Kenya
}

(Received 30 July 1957-Revised 27 December 1957)

In the course of extensive digestibility work at this station, the need became obvious for more critical studies into the effects of interaction of one component of the diet with the other constituents. The results of giving sheep fairly readily available carbohydrate supplements with some of the very coarse roughages so common in many parts of East Africa were conflicting. That interaction does occur under such feeding conditions is of course well known, but the excessive degree found to occur in local studies made it desirable to look further into this effect. In the course of such work information became available on the digestibility of the proximate constituents of the diet at various points along the alimentary tract and it is with this part of the work that this paper deals.

\section{EXPERIMENTAL}

Three experiments were conducted, one mature Masai-type sheep being used for each investigation.

\section{General procedure}

Exp. I. The sheep was given a daily ration of $600 \mathrm{~g}$ Rhodes-grass (Chloris gayana) hay in two equal feeds at 8 a.m. and 4 p.m.; food residues were collected daily before the morning feed. After 12 days' preliminary feeding a digestibility trial was begun and continued for 17 days. At all times during this period the sheep had free access to water. During the digestibility trial the daily procedure was as follows. The faeces were weighed, two $100 \mathrm{~g}$ samples were taken for moisture determinations and dried at $105^{\circ}$ to constant weight. Two further samples, each comprising one-fifth of the total daily faecal output were taken; one of these was dried at $60^{\circ}$ for analytical purposes and the other was saturated with ethyl alcohol and dried at $50^{\circ}$ for lignin determination. In addition, two $5 \mathrm{~g}$ samples of the wet faeces were analysed daily for nitrogen. The daily representative samples of the faeces taken for general analysis were bulked after drying but the daily samples taken for lignin determinations were stored and analysed individually. At $8 \mathrm{a} . \mathrm{m}$. on the day following the completion of the digestibility trial the sheep was killed with a pistol-type humane killer. The sheep's alimentary tract was removed as quickly as practicable, the various sections were tied off, excised and the contents of each removed, weighed and sampled with a minimum of delay. The tract was divided into the following eight sections: rumen, reticulum, omasum, abomasum, small intestine, caecum, colon and terminal colon with rectum. One sample was immediately weighed into a container and dried to constant weight at 
I0 $5^{\circ}$. A further sample was dried at $60^{\circ}$ for analysis and another sample was saturated with ethyl alcohol and dried at $50^{\circ}$ for lignin determination. Because of the very variable nature and differences in volume of the contents from the various sections of the tract no attempt was made to standardize the weights of the samples. Duplicate nitrogen determinations were also made on the fresh contents from each section of the gut. It will be understood that the period elapsing between the last feed and the removal of the digesta from the alimentary tract was about $\mathrm{I} 6 \mathrm{~h}$. This time interval was adopted very largely as a matter of convenience, no attempt being made to study the effect of time interval between last feed and slaughter on the chemical composition of the digesta from the alimentary tract. As only one animal on each of three diets was being studied it was thought that a long interval between the last feed and slaughter was likely to minimize the error arising from passage of recently ingested food.

Exp. 2. The sheep was given a daily ration of $500 \mathrm{~g}$ of the same hay as used in Exp. I, with $300 \mathrm{~g}$ ground cassava meal. The preliminary feeding period was 2 I days and the collection period itself lasted a further $\mathrm{I} 6$ days. Otherwise the procedure was exactly as in Exp. I.

Exp. 3. The sheep was very gradually introduced to a ration consisting of pure kibbled maize, hay being withdrawn over a period of some $3-4$ weeks. Food consumption was naturally rather low and became constant at about $300 \mathrm{~g} /$ day. The digestibility trial was begun when the sheep had been on a purely maize diet for $\mathbf{1} 8$ days, and lasted for 25 days. Again the procedure was as in Exp. 1.

\section{Preparation of samples and chemical methods}

Milling. All the dried samples were ground in a Wiley Intermediate Model Laboratory Mill (supplied by Arthur H. Thomas Co., Philadelphia, U.S.A.) to pass a 40-mesh screen.

Lignin. All feeds, feed residues, faeces and alimentary-tract samples were analysed for lignin by the method of Armitage, Ashworth \& Ferguson (I948).

Energy values. These were determined in a bomb calorimeter.

Nitrogen. The macro-Kjeldahl method was used.

Ash. Samples of the dried materials were ashed at $55^{\circ}-600^{\circ}$ in Vitreosil basins.

Silica. The method described in Fertilisers and Feeding Stuffs, Statutory Rules and Orders, 1932, no. 658, p. 29, was used.

Ether extractives. Samples ( $2 \mathrm{~g})$ were extracted for $6 \mathrm{~h}$ with light petroleum, b.p. $40-60^{\circ}$. After evaporation of the solvent, the oil was dried at $100^{\circ}$ and weighed.

Crude fibre. The extracted samples from the above determinations were used for crude-fibre estimations. The method used is described in Fertilisers and Feeding Stuffs, Statutory Rules and Orders, I932, no. 658, p. 27.

Nitrogen-free extractives. These represent the percentage of the dry matter remaining after subtraction of total ash, crude protein, ether extractives and crude fibre. 
RESULTS

\section{Lignin as tracer}

Considerable preliminary work was done to find the most satisfactory indigestible plant tracer for use in subsequent calculations of coefficients of partial digestibility. Chromogens were examined but were abandoned in favour of lignin, and eventually crude lignin, as determined by the method of Armitage et al. (1948), was chosen as providing the most nearly indigestible substance. Lignin, as determined by this method, when corrected for nitrogen, did not appear to be such a satisfactory tracer as its crude counterpart. Values are given in Table $I$ which illustrate the recovery of crude lignin in the faeces of the three experimental sheep; Table 2 shows the lignin content of the daily faecal samples from the three sheep, and indicates the constancy of the lignin fraction of the faecal output, a necessary pre-condition to the calculation of coefficients of partial digestibility.

Table I. Recovery of crude lignin in the faeces of the three sheep

$\begin{array}{clcc} & & \begin{array}{c}\text { Lignin } \\ \text { ingested } \\ \text { Exp. no. }\end{array} & \begin{array}{c}\text { Faecal } \\ \text { lignin } \\ (\mathrm{g})\end{array} \\ \text { I } & \text { Hay } & 1003 \cdot 4 & 998 \cdot 3 \\ 2 & \text { Hay with cassava } & 806 \cdot 8 & 814 \cdot 9 \\ 3 & \text { Maize } & 78 \cdot 4 & 90 \cdot 9\end{array}$

Table 2. Crude-lignin content of the faeces of the three sheep

\begin{tabular}{|c|c|c|c|}
\hline \multirow{2}{*}{$\begin{array}{c}\text { Day of } \\
\text { trial }\end{array}$} & \multicolumn{3}{|c|}{ Crude lignin on dry-matter basis ( $\%$} \\
\hline & Exp. I & Exp. 2 & Exp. 3 \\
\hline I & $21 \cdot 43$ & $19 \cdot 15$ & $9 \cdot \mathrm{II}$ \\
\hline 2 & $21 \cdot 72$ & 19.22 & $8 \cdot 89$ \\
\hline 3 & $21 \cdot 98$ & $19 \cdot 37$ & 9.42 \\
\hline 4 & $21 \cdot 79$ & $190^{\circ} 42$ & $9 \cdot 25$ \\
\hline 5 & $22 \cdot 16$ & $19 \cdot 36$ & $9 \cdot 45$ \\
\hline 6 & $22 \cdot 57$ & 19.48 & 9.19 \\
\hline 7 & $22 \cdot 90$ & 18.95 & $9 \cdot 17$ \\
\hline 8 & $21 \cdot 79$ & 18.79 & 9.00 \\
\hline 9 & $22 \cdot 44$ & $19^{\circ} 13$ & $9.4 \mathrm{I}$ \\
\hline 10 & $22 \cdot 22$ & $19 \cdot 32$ & 9.09 \\
\hline II & $22 \cdot 85$ & 19.29 & $9 \cdot 19$ \\
\hline 12 & $22 \cdot 45$ & 19.47 & $9 \cdot 23$ \\
\hline 13 & $22 \cdot 08$ & $19 \cdot 3^{6}$ & 9.04 \\
\hline 14 & $22 \cdot 07$ & $19 \cdot 20$ & $9^{\cdot 24}$ \\
\hline 15 & $2 \pi \cdot 49$ & $19 \cdot 14$ & $9 \cdot 38$ \\
\hline 16 & $2 I \cdot 9 \mathrm{I}$ & $19^{\circ} 43$ & $9 \cdot 16$ \\
\hline 17 & $23 \cdot 22$ & - & 9.33 \\
\hline 18 & - & - & $9^{\circ} \mathrm{I} 3$ \\
\hline 19 & 一 & - & $8 \cdot 97$ \\
\hline 20 & - & - & $8 \cdot 84$ \\
\hline $2 I$ & - & - & $9 \cdot 10$ \\
\hline 22 & - & - & $9 \cdot 3 \mathrm{I}$ \\
\hline 23 & 一 & - & 9.09 \\
\hline 24 & - & - & $9 \cdot 12$ \\
\hline 25 & - & - & $9 \cdot 15$ \\
\hline
\end{tabular}




\section{Changes along the digestive tract}

(I) From Table 3 it will be seen that the rumen and reticulum together contained, on a dry-matter basis, approximately two-thirds of the digesta found in the alimentary tract. The proportion found in the forestomach tended to increase as the amount of roughage in the diet decreased. The omasum retained progressively less material as the proportion of roughage in the diet was reduced.

Table 3. Moisture contents and dry weights of digesta from sections of the alimentary tracts of the three sheep

\begin{tabular}{|c|c|c|c|c|c|c|c|c|c|}
\hline \multirow[b]{2}{*}{ Section of tract } & \multicolumn{3}{|c|}{ Exp. I } & \multicolumn{3}{|c|}{ Exp. 2} & \multicolumn{3}{|c|}{ Exp. 3} \\
\hline & $\begin{array}{c}\text { Dry } \\
\text { matter } \\
(\%)\end{array}$ & $\begin{array}{l}\text { Weight } \\
\text { of dry } \\
\text { contents } \\
\text { (g) }\end{array}$ & $\begin{array}{l}\text { Organ } \\
\text { content as } \\
\text { percentage } \\
\text { of total } \\
\text { contents }\end{array}$ & $\begin{array}{c}\text { Dry } \\
\text { matter } \\
(\%)\end{array}$ & $\begin{array}{l}\text { Weight } \\
\text { of dry } \\
\text { contents } \\
\text { (g) }\end{array}$ & $\begin{array}{l}\text { Organ } \\
\text { content as } \\
\text { percentage } \\
\text { of total } \\
\text { contents }\end{array}$ & $\begin{array}{c}\text { Dry } \\
\text { matter } \\
(\%)\end{array}$ & $\begin{array}{l}\text { Weight } \\
\text { of dry } \\
\text { contents } \\
\text { (g) }\end{array}$ & $\begin{array}{c}\text { Organ } \\
\text { content as } \\
\text { percentage } \\
\text { of total } \\
\text { contents }\end{array}$ \\
\hline Rumen & $10 \cdot I$ & $350 \cdot 1$ & $52 \cdot 4$ & 10.5 & $321 \cdot 4$ & $55 \cdot 3$ & $18 \cdot 1$ & $346 \cdot 3$ & $68 \cdot 0$ \\
\hline Reticulum & II. 5 & 34.5 & $5 \cdot 2$ & 10.6 & $26 \cdot 8$ & $4 \cdot 6$ & $15 \%$ & $25 \cdot 7$ & $5 \cdot 0$ \\
\hline Omasum & $18 \cdot 8$ & $\begin{array}{l}3+3 \\
59.5\end{array}$ & $8 \cdot 9$ & $20 \cdot 8$ & $37 \cdot 0$ & $6 \cdot 4$ & $2 I \cdot 4$ & $5 \cdot x$ & r.o \\
\hline Abomasum & 15.5 & 19.0 & $2 \cdot 8$ & $140^{\circ}$ & $12 \cdot 5$ & $2 \cdot I$ & 9.4 & $22 \cdot 5$ & 4.4 \\
\hline Small intestine & $9 \cdot 8$ & $62 \cdot 0$ & $9 \cdot 3$ & II.OO & 44.9 & $7 \cdot 7$ & $5 \cdot 4$ & 29.9 & $5 \cdot 9$ \\
\hline Caecum & 13.5 & $43 \cdot 1$ & $6 \cdot 4$ & $12 \cdot I$ & $42 \cdot 6$ & $7 \cdot 3$ & $9 \cdot 7$ & 16.0 & $3 \cdot I$ \\
\hline Colon & 14.6 & 69.1 & 10.3 & $15 \cdot 1$ & $42 \cdot 9$ & $7 \cdot 4$ & ro.8 & $54 \cdot 5$ & 10.7 \\
\hline $\begin{array}{l}\text { Terminal colon } \\
\text { and rectum }\end{array}$ & $25^{\circ} 8$ & $3 \times 0$ & $4 \cdot 6$ & $28 \cdot 3$ & 53.5 & $9 \cdot 2$ & I $8 \cdot 0$ & $9 \cdot 5$ & $I \cdot 9$ \\
\hline Total & - & $668 \cdot 3$ & - & - & $5^{8 I} \cdot 6$ & - & - & $5 \circ 9 \cdot 5$ & - \\
\hline
\end{tabular}

(2) Comprehensive analyses of the alimentary-tract samples from the three sheep are given in Table 4 .

(3) Table 5 traces the combined effects of digestion, absorption, secretion and physical separation on $100 \mathrm{~g}$ feeding-stuff along the alimentary tracts of the three sheep. The results given in this table are derived from the use of the lignin-ratio technique. The calculation is illustrated in the footnote to Table 5 .

Consideration of the results in Tables 4 and 5 enables the following points to be noted:

(a) Reference to Table 5 shows that, in all but one instance, the nutrient values per $g$ of lignin in the contents of the reticulum exceed those in the contents of the rumen. The values for each organ are related to a fixed food intake by the use of lignin as an indigestible reference substance.

(b) Similarly, the nutrient values of the contents of the omasum are in all but two instances lower than the values for the reticulum, when related to food intake.

(c) Table 5 shows that the nutrient values of the contents of the abomasum of the sheep on the all-hay diet are higher than the values for the omasum, but these differences are not in evidence for the sheep in Exps. 2 and 3.

(d) The nutrient values of the contents from the small intestines of all three sheep indicate that a very considerable addition of non-fibrous nutrients took place in this section of the gut. The values in Table 6 demonstrate this point clearly.

(e) The values in Table 5 for the unabsorbed nutrients found in the contents of the 


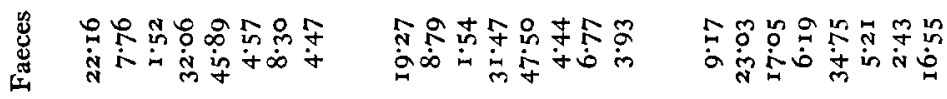

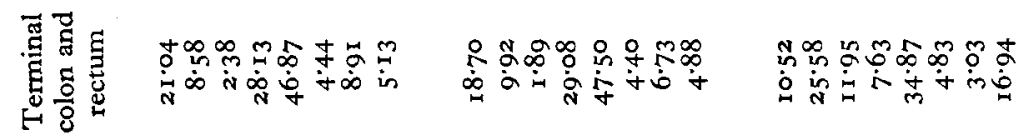

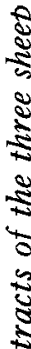

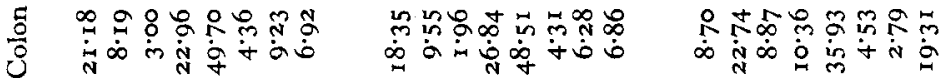

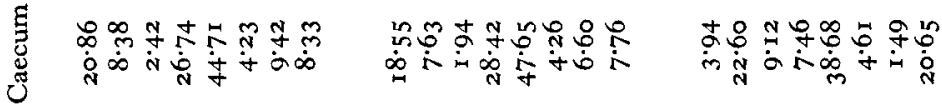

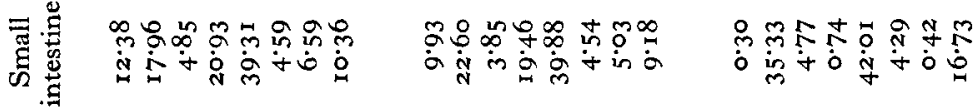

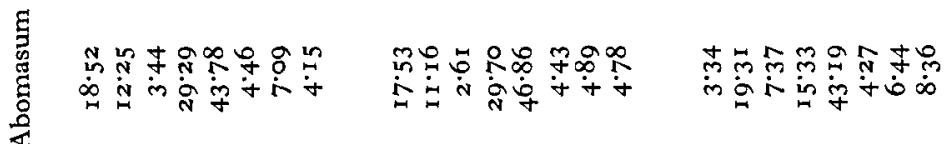

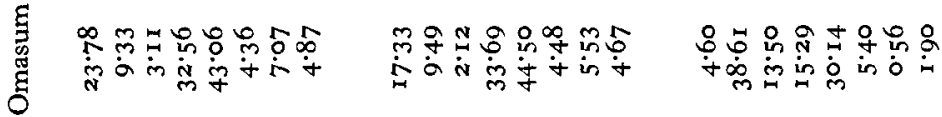

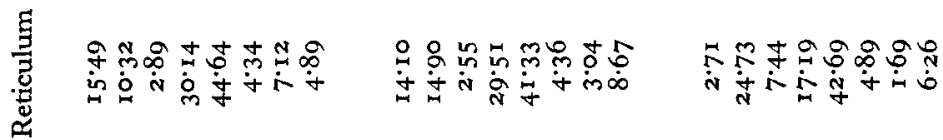

s

है

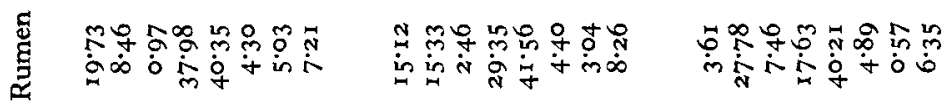

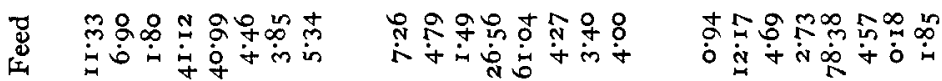

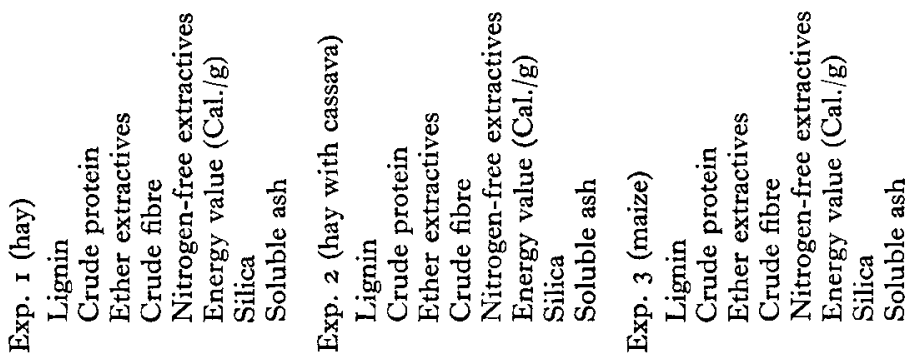




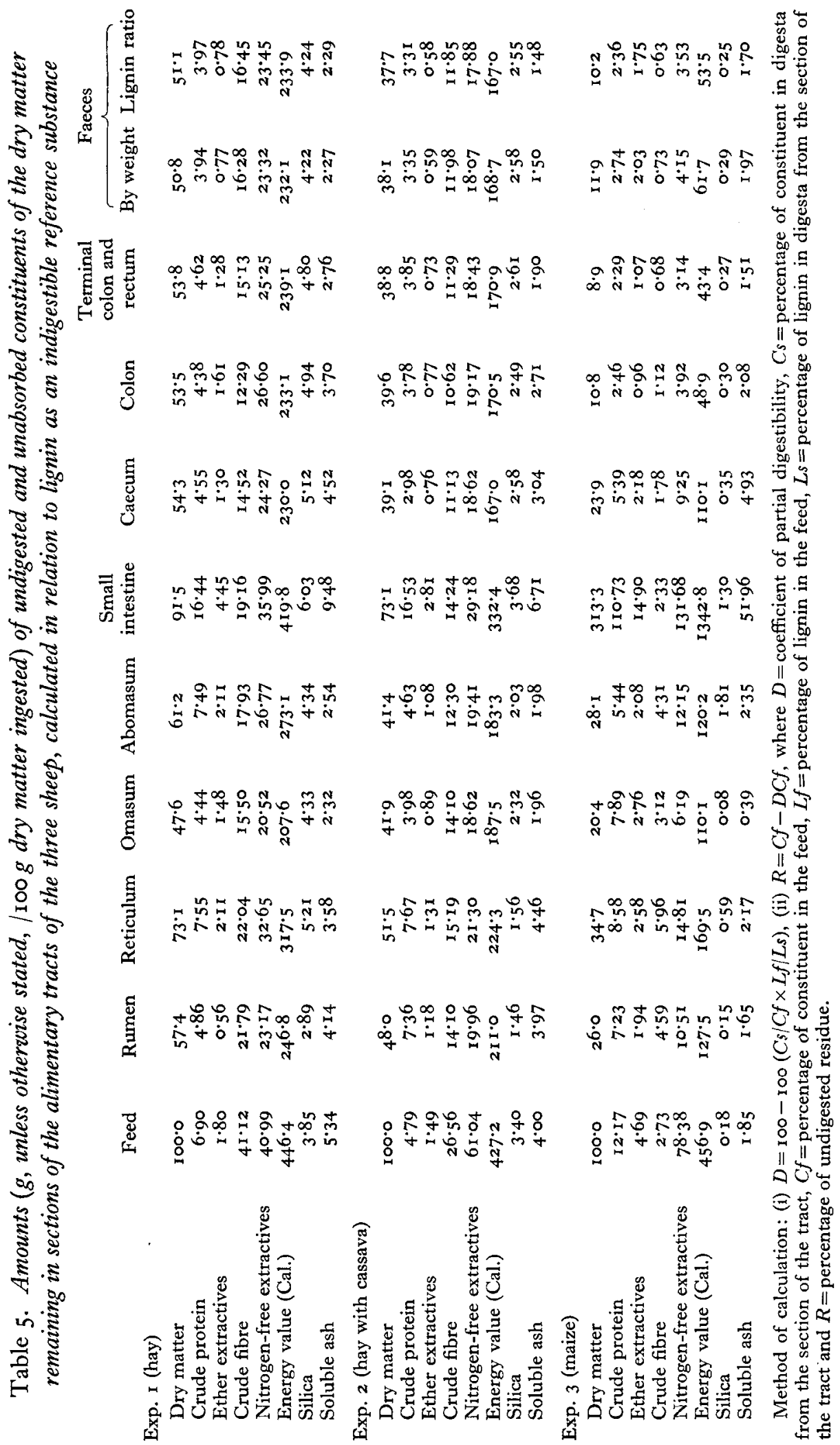


caecum derived from $100 \mathrm{~g}$ food ingested indicate that reabsorption of secreted materials during passage through the small intestine had been completed.

(f) The only significant change in the nutrient value of the digesta in passing from the caecum to the rectum, except with the sheep in Exp. 3, appeared to be the absorption of an appreciable quantity of soluble ash.

( $g$ ) The absorption of the soluble ash also appeared to be associated with a considerable absorption of water from the digesta, particularly in its passage through the terminal colon.

Table 6. Unabsorbed nutrients recovered from digesta of abomasum and small intestine of the three sheep, expressed as a percentage of ingested nutrients

Exp. I (hay)
Dry matter
Crude protein
Ether extractives
Crude fibre
Nitrogen-free extractives
Energy value
Silica
Soluble ash
Exp. 2 (hay with cassava)
Dry matter
Crude protein
Ether extractives
Crude fibre
Nitrogen-free extractives
Energy value
Silica
Soluble ash
Exp. 3 (maize)
Dry matter
Crude protein
Ether extractives
Crude fibre
Nitrogen-free extractives
Energy value
Silica
Soluble ash

$\begin{array}{rr}\text { Abomasum } & \begin{array}{r}\text { Small } \\ \text { intestine }\end{array} \\ 61 \cdot 2 & 91 \cdot 5 \\ 108 \cdot 6 & 238 \cdot 3 \\ 117 \cdot 2 & 247 \cdot 2 \\ 43 \cdot 6 & 46 \cdot 6 \\ 65 \cdot 3 & 87 \cdot 8 \\ 61 \cdot 2 & 94 \cdot 0 \\ 112 \cdot 7 & 156 \cdot 6 \\ 47 \cdot 6 & 177 \cdot 5 \\ & \\ 41 \cdot 4 & 73 \cdot 1 \\ 96 \cdot 7 & 345 \cdot 1 \\ 72 \cdot 5 & 188 \cdot 6 \\ 46 \cdot 3 & 53 \cdot 6 \\ 31 \cdot 8 & 47 \cdot 8 \\ 42 \cdot 9 & 77 \cdot 8 \\ 59 \cdot 7 & 108 \cdot 2 \\ 49 \cdot 5 & 167 \cdot 8 \\ & \\ 28 \cdot 1 & 313 \cdot 3 \\ 44 \cdot 7 & 909 \cdot 9 \\ 44 \cdot 4 & 317 \cdot 7 \\ 157 \cdot 9 & 85 \cdot 3 \\ 15 \cdot 5 & 168 \cdot 0 \\ 26 \cdot 3 & 293 \cdot 9 \\ 1005 \cdot 5 & 722 \cdot 2 \\ 127 \cdot 0 & 2808 \cdot 6\end{array}$

(h) With the exception of the absorption of the water referred to in $(g)$ the differences just reported only became obvious when the results were interpreted on a food-intake basis by use of the lignin-ratio method. Interpretation of the straightforward chemical analyses in Table 4 , though often giving a guide to probable absorption and secretion, did not, with any accuracy, demonstrate the extent of such activities.

\section{DISCUSSION}

Variations in the composition of digesta along the alimentary tract of the ruminant have received little attention in the past, probably largely on account of the complexities of the processes involved. Elsden, Hitchcock, Marshall \& Phillipson (I946) 
reported on the weight, moisture content and volatile fatty-acid content of digesta removed from consecutive parts of the alimentary tract of four sheep. They noted that the regions of the alimentary tract in which fermentation occurred were sharply defined and consisted of the reticulo-rumen and the large intestine. Gray (1947) investigated the extent of cellulose digestion at successive levels of the alimentary tract, using lignin determined by the method of Norman \& Jenkins (1934 $a, b$ ) as tracer, and came to the conclusion that $70 \%$ of the cellulose was broken down in the rumen, the remainder being broken down in the caecum and colon. No digestion of cellulose was found to occur in the abomasum or small intestine. More recent work by Weller \& Gray (1954) on starch digestion in the ruminant, using lignin as tracer, suggested that there might be extensive destruction of starch in the omasum. Gray, Pilgrim \& Weller (1954), using starch: lignin and nitrogen: lignin ratios, suggested that only very small amounts of reticular contents may pass indirectly to the omasum via the omasal groove and that little if any liquid is squeezed away mechanically from the solids in the omasum. Raynaud (I955), working on slaughterhouse animals, has provided information on nitrogen variations in the anterior sections of the digestive tract. Boyne, Campbell, Davidson \& Cuthbertson (I956) have published results obtained from twenty-one sheep killed at varying intervals of time after two equal feeds per day of hay and concentrates. The materials from the various sections of the alimentary tracts were analysed for various constituents and some suggestions were put forward from a consideration of the various concentration gradients. Balch (1957), working with cattle on a wide range of diets varying from all hay to almost all concentrates, has used a lignin-ratio technique to estimate the extent of digestion in the reticulo-rumen and in the remainder of the hind gut.

Many of these workers have emphasized the difficulties involved in trying to estimate the extent of digestion of any constituent in any section of the tract. As they point out, digestion is in every sense a dynamic process, many actions and reactions occurring simultaneously. Thus there may be food intake, food passage, nutrient absorption, fermentation, secretion and synthesis all going on side by side in the same organ. It follows that variations in the time of sampling of the digesta from the alimentary tract may produce very different results. This is well illustrated in the work of Boyne et al. (1956) and was also mentioned by Paloheimo, Mäkelä \& Salo (1955) in their comments on the work of Hale, Duncan \& Huffman (1940, 1947a, $b$ ) and Gray (1947). Most workers, however, agree that the errors introduced by intake of food, passage of food and the like, are most serious in the anterior part of the tract and greatly diminish in the intestinal sections. Hale et al. (1947a, b) found that digesta removed from the rumen $\mathrm{I} 4$ and $24 \mathrm{~h}$ after the last feed were almost identical in chemical composition, although half the dry matter present in the rumen at $14 \mathrm{~h}$ had passed from the rumen during the succeeding Io $h$. From this and other work reported there, Hale et al. (1947a,b) concluded that digestion in the rumen was completed in about $\mathrm{I} 2 \mathrm{~h}$. If this is substantially correct, and if one is not primarily concerned with rate of digestion, then one can study animals which have reached this post-rumen digestion phase to examine the site and extent of digestion in the lower sections of the alimentary tract. In other words, the rumen is then being used as a ready source of 
digesta, the composition of which should be reasonably constant. The time interval for the studies reported here was, as previously stated, about $16 \mathrm{~h}$. It may well be that some of the material found in the lower sections of the tract was derived from material passing more quickly through the rumen and having a higher nutritive value than that found in the rumen after a period of $I 2 \mathrm{~h}$ or more. In noting this possible error, it might be fair to consider the possibility of such material being rapidly digested in the anterior sections of the tract, thus resulting in a stabilized lignin value before the slaughter of the animal some $\mathrm{I} 6 \mathrm{~h}$ after the last feed.

The suggestion that the material remaining in the various sections of the tract may not have been derived from a representative sample of the diet as a whole is theoretically not tenable if the thesis is accepted that the lignin, used as an inert reference substance, passes through the alimentary tract at the same speed as the nutrients in question. But in practice, useful as lignin is as a tracer, it seems unjustifiable to assume that there is no preferential passage or retention of digesta of differing lignin content in the various sections of the alimentary tract. That all the lignin ingested must pass through each section at some time or other is indisputable but that there may be periodic concentration of lignin is clearly not impossible. As will be seen there are undoubtedly limitations to the use of such a method for estimating the site and extent of digestion of food passing down the tract but, until it is possible to sample, accurately and frequently, the digesta passing numerous points along the digestive tract, the method has its uses. Provided these sources of error are borne in mind, the implications of the results may now be considered.

The diets given in the three experiments were of widely different types, ranging from hay alone, through an intermediate diet of hay and cassava meal to a diet wholly of maize meal. The results suggest that $40 \%$ of the dietary dry matter was digested in the rumen by the sheep on the hay diet compared with $50 \%$ on the mixed diet and $75 \%$ on the concentrate ration. The results also indicate that approximately two-thirds of the total contents of the tract are to be found in the rumen and reticulum, a figure in accord with that given by Boyne et al. (1956), although the rumen of the sheep on the low-roughage diet contained a considerably higher proportion of the total digesta than that of the hay-fed animal, $68 \%$ as against $52 \%$. It may possibly be that this variation lies within the normal range of variability, and that the present indication arises because only three animals were studied. But a further point arises from study of the figures in Table 3 which makes such an explanation most unlikely. These figures show that the rumens of the sheep in Exps. I and 3 contained a similar amount of dry material, although the sheep in Exp. I was consuming twice as much dry matter/day. Further, the digestion of some $75 \%$ of the diet in the rumen of the sheep in Exp. 3 compared with only $40 \%$ for the sheep in Exp. I means that the retention time of digesta in the rumen of the maize-fed animal was greater than that of the sheep in Exp. I. The partially digested material in the rumen of the hay-fed sheep represents some $I \frac{1}{2}$ days' intake of food; the amount in the rumen of the sheep in Exp. 3 represents almost 5 days' intake. Whether the low rate of passage of ground material from the rumen, described by Balch (I950), could account for such accumulation seems open to some doubt, although his findings seem more in keeping with these results than do 
those of Blaxter, Graham \& Wainman (1956) who, working with dried grass finely ground and in the long state, found that the ground material passed more quickly through the digestive tract. Blaxter et al. (1956), however, also noted that increasing the feeding level increased the rate of passage of the digesta. If this finding is generally applicable then the maize-fed sheep, receiving only about $300 \mathrm{~g}$ daily, would have a markedly lower rate of passage than the hay-fed animal. One further point may be of interest. Balch (1950) observed that when all the hay in the diet was ground the contents of the ventral parts of the reticulo-rumen were drier than when the cows were eating the same diets containing unground hay. The dry-matter content of the rumen digesta from the maize-fed sheep was $18 \%$ compared with $10 \%$ for the hayfed animal.

The dry-matter content of the other sections of the alimentary tract was generally variable, with the exception of the omasum. This organ contained progressively less digesta as the proportion of roughage in the diet was reduced.

The 'apparent' absorption of nutrients from the omasum correlated with the rise in lignin content may be ascribed in part to retention of material of lower nutritive value. Although this possibility cannot be entirely discounted, it would seem that onward passage or absorption must account for most of the observed differences, as it will be noted that the amount of crude fibre in the omasum per $100 \mathrm{~g}$ food ingested showed a considerable decline from the value found for the reticulum. It would seem reasonable to suppose that any concentration of fibrous material in the omasum would at least result in a slight corresponding rise in the crude-fibre content of this organ. Boyne et al. (1956) stated that their results indicated a loss of over $40 \%$ of the moisture content of the digesta on passing through the omasum. My results are in fair agreement with this figure. It may be that this dehydration is brought about by preferential passage of liquid digesta to the abomasum as tentatively suggested by Boyne et al. (1956), which would also account for the removal of digested nutrients from the omasum thus resulting in the considerable 'apparent' absorption referred to above.

In Exps. I and 2 no enhanced nitrogen concentration, compared with that of the other constituents, was observed in the omasum digesta, which is at variance with the results reported by Boyne et al. (1956). Again, contrary to their findings, the secretion of gastric juice into the abomasum had apparently increased the concentration of nitrogen in this organ when hay and hay with cassava were given, but had had no effect on the concentration of soluble ash. On the maize diet, however, a very considerable reduction of nitrogen, fat and energy concentration of the digesta in the abomasum was observed, together with a very greatly increased concentration of soluble ash.

When the values for nutrient concentrations are translated, by use of the lignin-ratio formula, into terms of unabsorbed or undigested nutrients or both per $100 \mathrm{~g}$ of diet ingested a somewhat different picture is found. On the diets of hay and hay with cassava the soluble ash remained unaffected by the secretion of gastric juices, whereas only the nitrogen fraction of the abomasum contents from the sheep fed on the hay diet was increased. The reduction in nitrogen content of the abomasum digesta from the maize-fed animal was much less marked and the energy value of the abomasum 
contents actually higher than the value for the omasum digesta, this result being in accord with the values for the hay-fed animal.

Analytical data relating to the small intestine illustrate that from the aspect of simple concentration gradient there was an increase of about $50 \%$ in the nitrogen content of the digesta of the small intestine over that from the abomasum contents of the sheep fed on hay alone. In the sheep fed on hay with cassava or on maize alone these differences approximated to $100 \%$. Considerable though these gradients are, they are still relatively small in comparison with the actual weight of protein found in the small intestine as against the weight found in the abomasum or the food itself, when related by means of the lignin-ratio formula to $100 \mathrm{~g}$ diet ingested. Thus the animal fed on hay alone derived $6.90 \mathrm{~g}$ crude protein from $100 \mathrm{~g}$ dry weight of feed. The addition of a small amount of nitrogenous material, possibly by secretion or by abrasion of the alimentary tract, raised the amount of protein, still derived from the ingestion of $100 \mathrm{~g}$ dry matter, to $7.49 \mathrm{~g}$. The secretions then entering the small intestine were sufficient to raise this figure to $16.44 \mathrm{~g}$, an increase of some $140 \%$ over the amount of protein found in the food. With the sheep fed on hay with cassava the differences were even greater, the three figures for feed, abomasum and small intestine being $4.79,4.63$ and $16.53 \mathrm{~g}$ respectively, an increase from feed to small intestine of some $245 \%$. For the sheep fed on maize alone the figures were $12 \cdot 17,5.44$ and I I $0.73 \mathrm{~g}$ respectively, an increase of about $800 \%$ from feed to small intestine and of about $2000 \%$ from abomasum to small intestine. It might be suggested that, owing to the very small amount of lignin found in the small intestine, estimates based on the lignin ratio would be rather unreliable. This may well be so although one rather important point does come out of a consideration of the results of Exp. 3 (Table 5) which tends to suggest that the lignin ratio gave a reasonable estimate of 'digestion and secretion' in the small intestine. The amount of crude fibre in the small intestine derived from roo $\mathrm{g}$ maize ingested, calculated by the lignin-ratio technique, appears to be very reasonable when compared with the amount found in the digesta from the abomasum and caecum.

In addition to this increase in nitrogenous material, similar to that observed by Boyne et al. (1956), very considerable additions of ether extractives and nitrogen-free extractives have taken place during passage through the small intestine. Such increases resulted in a very considerable gain in the calorific value of the digesta and of course in the dry-matter content. It will be understood that in this context the 'dry-matter content' refers to the actual dry weight of digesta found in the small intestine associated with the ingestion of $100 \mathrm{~g}$ feed dry matter and related to the contents of the small intestine by the lignin-ratio formula.

The picture of digestion in the sections of the alimentary tract posterior to the small intestine, is, by comparison with the foregoing, relatively straightforward. Absorption of almost all the digestible nutrients has taken place by the time the caecum is reached, the only significant absorption taking place in the sheep in Exps. I and 2 being the removal of about half the remaining soluble ash. The absorption in the sheep fed entirely on maize was a little more extensive, protein, carbohydrate and soluble ash all being removed in significant amounts. 
Some degree of dehydration took place during the passage of the digesta from the small intestine to the caecum, but it was observed that the bulk of the water was removed from the digesta during its passage through the terminal section of the colon. This dehydration was not associated with any further absorption of digested nutrients, with the notable exception of a small amount of soluble mineral matter.

\section{SUMMARY}

I. Three sheep were fed on three different rations, namely: (a) Rhodes-grass (Chloris gayana) hay, (b) Rhodes-grass hay with cassava meal, and (c) maize meal. After digestibility trials, during which it was possible to study the reliability, necessary for future calculations, of the faecal lignin content, the three animals were killed. The alimentary tracts were separated into the following parts: rumen, reticulum, omasum, abomasum, small intestine, caecum, colon, and terminal colon with rectum. The contents of each section were weighed and analysed for dry matter, lignin, crude protein, ether extractives, crude fibre, silica, soluble ash, nitrogen-free extractives and energy value.

2. Crude lignin determined by the method of Armitage et al. (1948) was used as the indigestible reference substance.

3. The rumen and reticulum together contained, on a dry-matter basis, approximately two-thirds of the digesta found in the alimentary tract. There were indications that, as the amount of roughage in the diet decreased, the proportion of digesta found in these organs increased and the proportion in the omasum and small intestine decreased.

4. A large degree of 'apparent' absorption took place from the rumen. The implications of 'apparent' absorption including, as it does, passage of food, fermentation, nutrient absorption, secretion and possibly synthesis, are discussed.

5. Extensive 'apparent' absorption of both nutrients and water took place from the omasum. Retention of material of lower nutritive value in the omasum does not appear to account for the differences observed.

6. Secretions into the small intestine resulted in greater quantities of digestible nutrients in the contents of this section than in those of the abomasum and, in some instances, an even greater weight of wet digesta was found than the weight of food ingested. Increases in the quantity of nitrogenous material constituted the greatest change although increases in fat and carbohydrate content, together with the higher protein value, resulted in substantially enhanced energy value. The increases in soluble-ash concentrations were also very significant, being particularly so with the maize-fed animal.

7. Absorption of nutrients was almost completed by the time the caecum was reached. In Exps. I and 2 only soluble ash was absorbed in measurable amounts in tract sections posterior to the caecum, but in Exp. 3 absorption was a little more extensive, both protein and carbohydrate, in addition to soluble ash, being removed in small amounts. Apart from a small amount of absorption from the caecum, most of the dehydration occurred in the terminal colon, where a significant amount of soluble mineral matter was also absorbed. 
I am indebted to Dr H. M. French for his help and advice given on numerous occasions during the course of the experiments, and to the Director, East African Veterinary Research Organization for permission to publish.

Footnote added 17 December 1957. Since this paper was prepared, Badawy, Campbell, Cuthbertson \& Fell (1957) have described preliminary observations on the marked shedding of the epithelium-mainly in the first quarter of the small intestine, from sheep shot in the frontal region with a captive bullet fired from a humane killer. These workers suggest that this shedding of the epithelium may, in part, account for the large apparent addition of nitrogen to the digesta in the small intestine when sheep killed in this way are studied. This observation may well have some bearing on the high nitrogen concentrations found in the intestinal digesta of the three sheep studied in the experiments reported here.

\section{REFERENCES}

Armitage, E. R., Ashworth, R. de B. \& Ferguson, W. S. (1948). F. Soc. chem. Ind., Lond., 67, $24 \mathrm{I}$. Badawy, A. M., Campbell, R. M., Cuthbertson, D. P. \& Fell, B. F. (1957). Nature, Lond., 180, 756. Baich, C. C. (1950). Brit. $¥$. Nutr. 4, 36r.

Balch, C. C. (1957). Brit. F. Nutr. Ir, 2 I3.

Blaxter, K. L., Graham, N. McC. \& Wainman, F. W. (1956). Brit. F. Nutr. ro, 69.

Boyne, A. W., Campbell, R. M., Davidson, J. \& Cuthbertson, D. P. (1956). Brit. F. Nutr. xo, 325.

Elsden, S. R., Hitchcock, M. W. S., Marshall, R. A. \& Phillipson, A. T. (1946). F. exp. Biol. 22, 191.

Gray, F. V. (1947). F. exp. Biol. 24, I5.

Gray, F. V., Pilgrim, A. F. \& Weller, R. A. (1954). F. exp. Biol. 31, 49.

Hale, E. B., Duncan, C. W. \& Huffman, C. F. (1940). F. Dairy Sci. 23, 953.

Hale, E. B., Duncan, C. W. \& Huffman, C. F. (1947a). F. Nutr. 34, 733.

Hale, E. B., Duncan, C. W. \& Huffman, C. F. (1947 b). F. Nutr. 34, 747.

Norman, A. G. \& Jenkins, S. H. (1934a). Biochem. F. 28, 2 147.

Norman, A. G. \& Jenkins, S. H. (1934b). Biochem. F. 28, 2 160.

Paloheimo, L., Mäkelä, A. \& Salo, M.-L. (1955). Maataloust. Aikakausk. 27, 70.

Raynaud, P. (1955). Arch. Sci. physiol. 9, 35.

Weller, R. A. \& Gray, F. V. (r954). F. exp. Biol. 3r, 40. 